\title{
Ammonia-Water mixture Property Code (AWProC) development, verification and Kalina cycle design for nuclear power plant
}

\author{
Mingjun Wang ${ }^{1,2}$, Annalisa Manera ${ }^{2 *}$, Suizheng Qiu $^{1 *}$, G.H. Su ${ }^{1}$ \\ (1. Department of Nuclear Science and Technology, Xi'an Jiaotong University, Xi'an 710049, China; \\ 2. Department of Nuclear Engineering and Radiological Sciences, University of Michigan, Ann Arbor, MI \\ 48109, USA) \\ Prof. Manera: manera@umich.edu; Prof. Qiu: szqiu@mail.xjtu.edu.cn
}

\begin{abstract}
The improvement of thermodynamic efficiency of power plants is of great interest for the whole energy industry. The use of Kalina cycle has a great potential to improve the thermal efficiency of a nuclear power plant. This cycle uses a mixture of ammonia and water as working fluid. In this paper, we discuss the development of an Ammonia-Water mixture Property Code (AWProC). The estimation of the mixture properties are based on the Gibbs free energy functions. The code is verified and validated against experimental data available in the literature and REFPROP code. It is shown that AWProC can accurately estimate the thermodynamic properties of ammonia-water mixtures over a wide range of conditions, including high temperature and pressure region. The code is then used to investigate the feasibility of applying the Kalina cycle to a typical Pressurizer Water Reactor (PWR) plant as an effective way to improve the plant efficiency. The fundamental of Basic-Kalina (B-K) cycle is described in detail firstly. Then, two modified configurations, Recuperation-Kalina (R-K) and Flash-Kalina (F-K) cycles respectively, are proposed for a typical 1000 MWe PWR. The simulation results indicate that the R-K type cycle can reach about $31.2 \%$ efficiency with simple equipment requirements, while the F-K type cycle can reach efficiencies up to about $34.8 \%$, but at the expenses of a slightly more complex design. The present work demonstrates the applicability of the Kalina cycle as a way to improve the thermal efficiency of a nuclear power plant. This concept is meaningful for improving nuclear power plants economic and competitiveness.
\end{abstract}

Key words: Ammonia-water mixture, Property code, Kalina cycle design, Efficiency calculation 


\section{NOMENCLATURE}

Variables

$v$

$C_{p}$

G

$R$

$P$

$T$

$h$

$s$

$x$

$A, B, C, D, E, m, n, a$

\section{Scripts}

$l$

$g$

$o$

$r$

E

I

$B$
Specific volume

Specific heat at constant pressure

Gibbs free energy function

Universal gas constant

Pressure

Temperature

Enthalpy

Entropy

Ammonia mass fraction

Coefficients

Liquid phase

Vapor phase

Ideal gas state

Ratio between actual value and the reference point value Gibbs excess energy

Indicator

Reference state

\section{Introduction}

The thermodynamic cycle employed for the conversion of thermal energy into electricity is an important design aspect of a power plant. Achieving high thermodynamic efficiency is very beneficial, since it implies either an increase of the electric power for a given reactor core thermal power, or a reduction of the total thermal power to be produced in the reactor core for a given output electric power. In the latter case, a lower decay heat would be produced with a consequent smaller load on the safety systems. The environmental footprint associated to the plant is another significant reason to reduce the total thermal power. Current Light Water reactor (LWR) designs utilize the Rankine cycle for the conversion of thermal power. A novel thermodynamic cycle, Kalina, has been recently proposed and successfully employed in geothermal plants $[1,2,3]$ to achieve very high (up to 50\%) thermal efficiencies. Current applications are characterized by low operating pressures and temperatures, and by relatively small power outputs. The working fluid of Kalina cycle is a binary mixture of water-ammonia. Generally, binary mixtures boil and condense at increasing and decreasing temperatures respectively, while pure component fluids (e.g. pure water) boil and condense at constant 
temperatures [4]. So the advantage of the Kalina cycle is that the heat transfer takes place at a variable temperature because the mixture bubble temperature and dew temperature depend on the fraction of ammonia within the mixture, as shown in Figure 1. The reason for the higher efficiency of the Kalina cycle with respect to a Rankine cycle can be easily understood by comparing the two cycles in a $T-S$ diagram, as illustrated in Figure 2 and Figure 3. Obviously, the Kalina cycle is more efficient than Rankine cycle when the same boundary conditions are applied. This is because for a binary mixture boiling and condensation occur at a variable temperature.

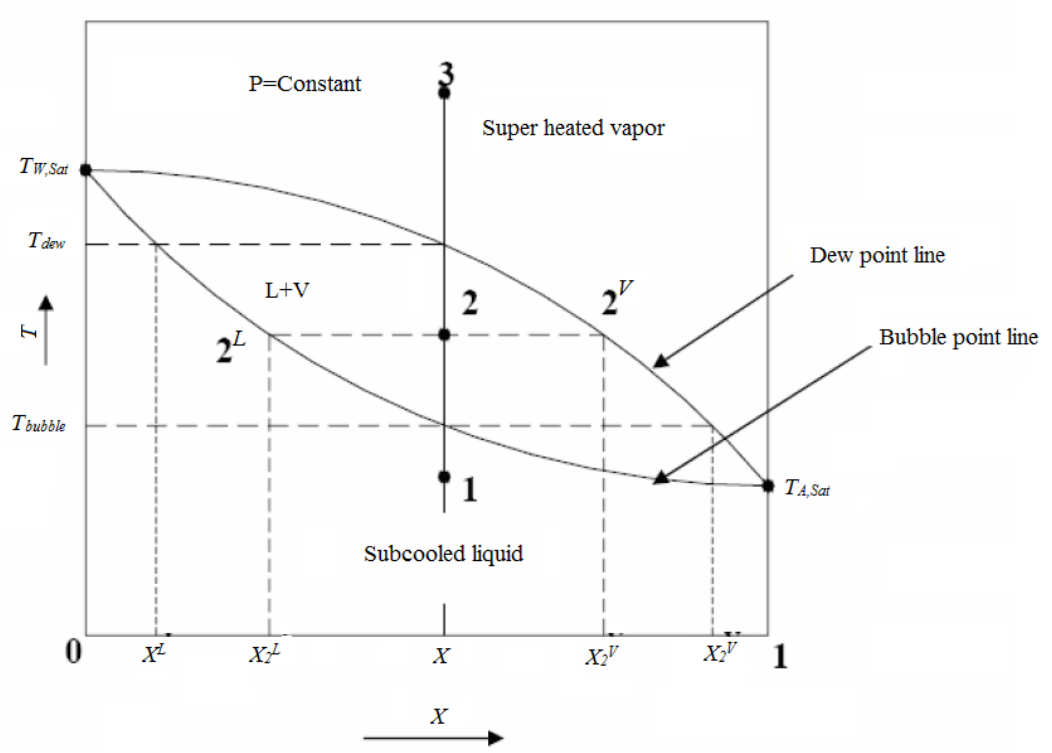

Fig. 1 Variation of bubble temperature and dew temperature with the ammonia mass fraction

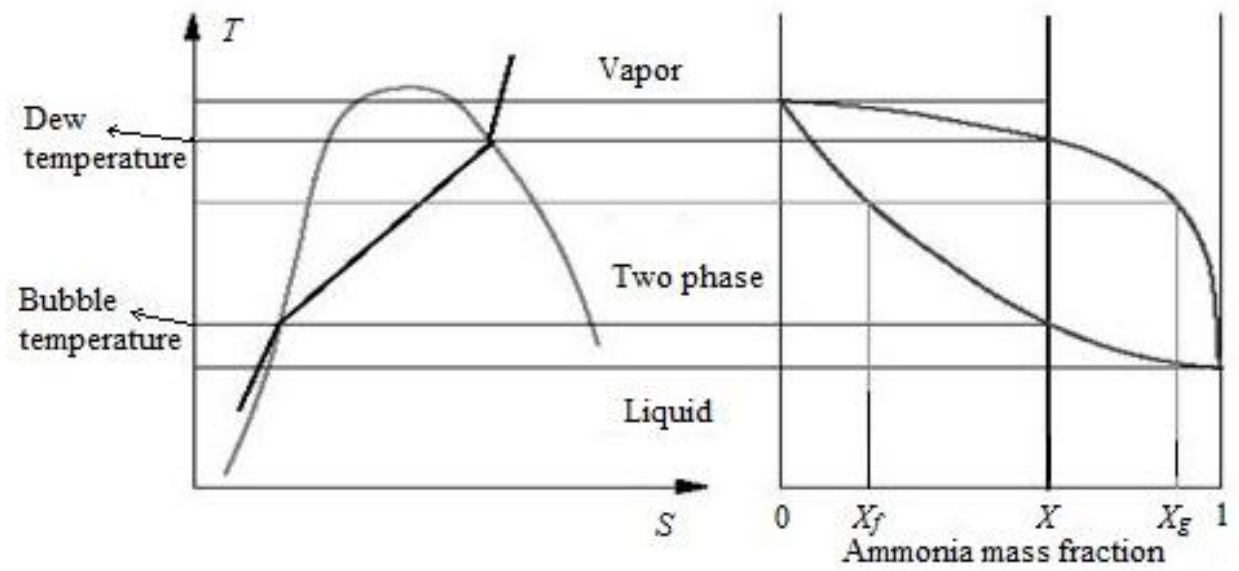

Fig. 2 Ammonia-water mixture working $T-S$ diagram 


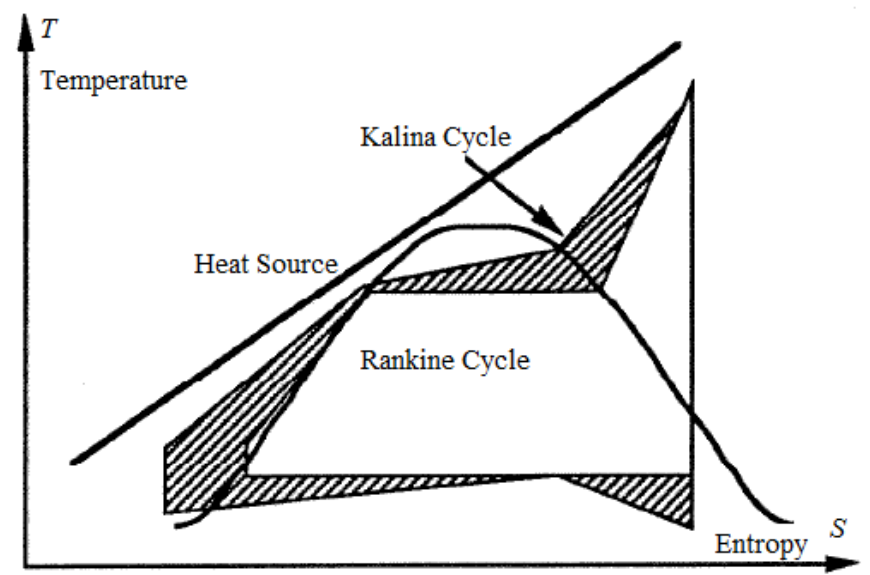

Fig. 3 T-S diagram comparison of Kalina cycle and Rankine cycle [5]

In order to analyze the efficiency of the Kalina cycle, it is necessary to estimate the thermodynamic properties of the ammonia-water mixture at different operating conditions. Several correlations for the ammonia-water mixture properties have been developed and published in the literature. The theoretical framework at the basis of the available correlations can be classified into nine groups: cubic equations of state [6], virial equations of state [7], Gibbs excess energy [8], corresponding states method [9], perturbation theory [10], group contribution theory [11], Leung-Griffiths model [12], Helmoltz free energy [13] and polynomial functions [14]. Ziegler and Trepp [15] described an equation for the thermodynamic properties of ammonia-water mixture in absorption units. In their work, the Gibbs excess energy equation was utilized for determining the specific enthalpy, specific entropy and specific volume. They developed the properties up to a pressure of 50 bars and temperature of $500 \mathrm{~K}$.

Also, for the Kalina cycle, several research efforts have been dedicated to its application. The original design concept known as Kalina Cycle System 1 (KCS 1) was published in 1984. The original Kalina concept was then modified in order to better match the working fluid and the heat-source heat-temperature curves in the boiler. This variant, known as KCS 6, achieves a 10\% efficiency improvement over the initial KCS 1. KCS 1 is preferable for small units (below 20 MW total power output; about $8 \mathrm{MW}$ as bottoming cycle), while the more sophisticated KCS 6 variant is preferable for larger units [16]. Hettiarachchi et al. [17] analyzed the performance of the Kalina cycle system 11 (KCS 11) with low-temperature geothermal heat sources, and studied the effect of the ammonia fraction and turbine inlet pressure on the overall cycle performance. 
The KCS 11 design has recuperator in the turbine exhaust steam before flowing to condenser. They found that, for a given turbine inlet pressure, an optimum ammonia fraction exists, which yields the maximum cycle efficiency.

Later a Kalina cycle with ejector (E-Kalina cycle) was proposed by Xinguo and collaborators [18]. In the E-Kalina cycle, an ejector is used to replace the throttle valve and the absorber used in the Kalina cycle system 11 (KCS 11). Results show that the net power output and thermal efficiency of the EKalina cycle are higher than that of the KCS 11. Zhang et al. [19] presented a detailed review of the research performed on the Kalina cycle, including the different variants of the Kalina cycle, the comparison with the Rankine cycle, and energy and exergy analyses. Rogdakis and Antonopoulos [20] proposed a triple stage power cycle which is similar to the Kalina cycle. However, they replaced the distillation condensation of the Kalina cycle with an absorption condensation process. Kouremenos et al. [21] analyzed this absorption type of power cycle as a bottoming cycle with a gas turbine topping cycle. Since this cycle still uses waterammonia vapor mixtures going through the turbine, the exit temperature must be relatively high in order to avoid condensation in the turbine.

Above all, for ammonia water mixture property, most papers describe it in a limited pressure range and generally at relatively low pressures. However, a very broad range of pressures is required, since we want to apply Kalina to a PWR. And the most previous Kalina studies were focused on the low powers and low pressures and the work in this paper investigates the feasibility of the Kalina cycles at high powers, pressures, and temperatures typical for nuclear power plants. Based on the nuclear power plant development requirements, an approach based on the Gibbs free energy functions is described in this paper. The equations reported in chapter 2 are then implemented in the AWProC (Ammonia-Water mixture Property Code) in-house code. In chapter 3 comparisons between the code calculations and published experimental data and REFPROP code calculations [22] are presented. Then different Kalina cycle configurations, including basic and modified versions, are proposed and their applicability to a typical 1000 MWe PWR plant is investigated. The calculations of the cycle thermal efficiency of proposed cycle types are carried out using AWProC in chapter 4. 


\section{AWProC development}

\subsection{Gibbs Free Energy Function}

The Gibbs free energy equation for a pure component is shown as:

$$
G=h_{0}-T s_{0}+\int_{T_{0}}^{T} C_{p} d T+\int_{P_{0}}^{P} v d P-T \int_{T_{0}}^{T}\left(C_{p} / T\right) d T
$$

Based on the empirical relations of $\mathrm{v}$ and $\mathrm{Cp}$, the following equations can be derived for the liquid phase and vapor phase, respectively.

For the liquid phase:

$$
\begin{aligned}
& G_{r}^{L}=h_{r, 0}^{L}-T_{r} s_{r, 0}^{L}+B_{1}\left(T_{r}-T_{r, 0}\right)+\left(B_{2} / 2\right)\left(T_{r}^{2}-T_{r, 0}^{2}\right)+ \\
& \left(B_{3} / 3\right)\left(T_{r}^{3}-T_{r, 0}^{3}\right)-B_{1} T_{r} \ln \left(\frac{T_{r}}{T_{r, 0}}\right)- \\
& B_{2} T_{r}\left(T_{r}-T_{r, 0}\right)-\left(B_{3} / 2\right) T_{r}\left(T_{r}^{2}-T_{r, 0}^{2}\right)+ \\
& \left(A_{1}+A_{3} T_{r}+A_{4} T_{r}^{2}\right)\left(P_{r}-P_{r, 0}\right)+\left(A_{2} / 2\right)\left(P_{r}^{2}-P_{r, 0}^{2}\right)
\end{aligned}
$$

For the vapor phase:

$$
\begin{aligned}
& G_{r}^{g}=h_{r, 0}^{g}-T_{r} s_{r, 0}^{g}+D_{1}\left(T_{r}-T_{r, 0}\right)+\left(D_{2} / 2\right)\left(T_{r}^{2}-T_{r, 0}^{2}\right)+ \\
& \left(D_{3} / 3\right)\left(T_{r}^{3}-T_{r, 0}^{3}\right)-D_{1} T_{r} \ln \left(\frac{T_{r}}{T_{r, 0}}\right)-D_{2} T_{r}\left(T_{r}-T_{r, 0}\right)- \\
& \left(D_{3} / 2\right) T_{r}\left(T_{r}^{2}-T_{r, 0}^{2}\right)+T_{r} \ln \left(\frac{P_{r}}{P_{r, 0}}\right)+C_{1}\left(P_{r}-P_{r, 0}\right)+ \\
& C_{2}\left(\frac{P_{r}}{T_{r}^{3}}-4 \frac{P_{r, 0}}{T_{r, 0}^{3}}+3 \frac{T_{r} P_{r, 0}}{T_{r, 0}^{4}}\right)+C_{3}\left(\frac{P_{r}}{T_{r}^{11}}-12 \frac{P_{r, 0}}{T_{r, 0}^{11}}+11 \frac{T_{r} P_{r, 0}}{T_{r, 0}^{12}}\right)+ \\
& \left(\frac{C_{4}}{3}\right)\left(\frac{P_{r}^{3}}{T_{r}^{11}}-12 \frac{P_{r, 0}^{3}}{T_{r, 0}^{11}}+11 \frac{P_{r, 0}^{3} T_{r}}{T_{r, 0}^{12}}\right)
\end{aligned}
$$

Where the subscript o means the ideal gas state, the $\mathrm{Tr}$, $\operatorname{Pr}$ and $\mathrm{Gr}$ are the ratio between a parameter actual value and the reference point value, and are expressed as:

$$
\begin{gathered}
T_{r}=T / T_{B} \\
P_{r}=P / P_{B} \\
G_{r}=G / R T_{B}
\end{gathered}
$$

The reference values for the above equations are $R=8.314 \mathrm{~J} / \mathrm{mol} \cdot \mathrm{K}, T_{B}=100 \mathrm{~K}$ and $P_{B}=10$ bar. The coefficients in the equations are listed in Table 1 [23].

Table 1 Coefficients for the equations of the pure components 


\begin{tabular}{ccc}
\hline Coefficient & Ammonia & Water \\
\hline$A_{1}$ & $3.971432 \mathrm{e}-2$ & $2.748796 \mathrm{e}-2$ \\
$A_{2}$ & $-1.790557 \mathrm{e}-5$ & $-1.016665 \mathrm{e}-5$ \\
$A_{3}$ & $-1.308905 \mathrm{e}-2$ & $-4.452025 \mathrm{e}-3$ \\
$A_{4}$ & $3.752836 \mathrm{e}-3$ & $8.389246 \mathrm{e}-4$ \\
$B_{1}$ & $1.634519 \mathrm{e} 1$ & $1.214557 \mathrm{e} 1$ \\
$B_{2}$ & -6.508119 & -1.898065 \\
$B_{3}$ & 1.448937 & $2.911966 \mathrm{e}-1$ \\
$C_{1}$ & $-1.049377 \mathrm{e}-2$ & $2.136131 \mathrm{e}-2$ \\
$C_{2}$ & -8.288224 & $-3.169291 \mathrm{e} 1$ \\
$C_{3}$ & $-6.647257 \mathrm{e} 2$ & $-4.634611 \mathrm{e} 4$ \\
$C_{4}$ & $-3.045352 \mathrm{e} 3$ & 0.0 \\
$D_{1}$ & 3.673647 & 4.019170 \\
$D_{2}$ & $9.989629 \mathrm{e}-2$ & $-5.175550 \mathrm{e}-2$ \\
$D_{3}$ & $3.617622 \mathrm{e}-2$ & $1.951939 \mathrm{e}-2$ \\
$h_{l}$ & 4.878573 & 21.821141 \\
$h_{g}$ & 26.468879 & 60.965058 \\
$s_{l}$ & 1.644773 & 5.733498 \\
$S_{g}$ & 8.339026 & 13.453430 \\
$T_{0}$ & 3.2252 & 5.0705 \\
$P_{0}$ & 2.000 & 3.000 \\
\hline
\end{tabular}

The pure component molar specific enthalpy, entropy and volume equations can be derived from the general Gibbs free energy functions of the pure component, as:

$$
\begin{aligned}
& h=-R T_{B} T_{r}^{2}\left[\frac{\partial}{\partial T_{r}}\left(G_{r} / T_{r}\right)\right]_{P_{r}} \\
& s=-R\left[\frac{\partial G_{r}}{\partial T_{r}}\right]_{P_{r}} \\
& v=\frac{R T_{B}}{P_{B}}\left[\frac{\partial G_{r}}{\partial T_{r}}\right]_{T_{r}}
\end{aligned}
$$

The derivation of the ammonia-water mixture properties on the basis of the Gibbs free energy functions is described in the following chapters.

\subsection{Ammonia Water Mixture Property Calculation}

The mixture properties equations of vapor phase and liquid phase derived from the pure component property functions are:

For the vapor phase,

$$
h_{m}^{g}=x_{g} h_{a}^{g}+\left(1-x_{g}\right) h_{w}^{g}
$$




$$
\begin{aligned}
& s_{m}^{g}=x_{g} s_{a}^{g}+\left(1-x_{g}\right) s_{w}^{g}+s^{m i x} \\
& v_{m}^{g}=x_{g} v_{a}^{g}+\left(1-x_{g}\right) v_{w}^{g}
\end{aligned}
$$

For the liquid phase,

$$
\begin{aligned}
& h_{m}^{L}=x_{f} h_{a}^{L}+\left(1-x_{f}\right) h_{w}^{L}+h^{E} \\
& s_{m}^{L}=x_{f} s_{a}^{L}+\left(1-x_{f}\right) s_{w}^{L}+s^{E}+s^{m i x} \\
& v_{m}^{L}=x_{f} v_{a}^{L}+\left(1-x_{f}\right) v_{w}^{L}+v^{E}
\end{aligned}
$$

Where the $h^{E}, s^{E}, v^{E}$ and $s^{m i x}$ are derived from:

$$
\begin{gathered}
h^{E}=-R T_{B} T_{r}^{2}\left[\frac{\partial}{\partial T_{r}}\left(G_{r}^{E} / T_{r}\right)\right]_{P_{r, x}} \\
s^{E}=-R\left[\frac{\partial G_{r}^{E}}{\partial T_{r}}\right]_{P_{r, x}} \\
v^{E}=\frac{R T_{B}}{P_{B}}\left[\frac{\partial G_{r}^{E}}{\partial T_{r}}\right]_{T_{r, x}} \\
s^{m i x}=-R\left[x_{f} \ln \left(x_{f}\right)+\left(1-x_{f}\right) \ln \left(1-x_{f}\right)\right]
\end{gathered}
$$

The $G r^{E}$ equation is:

$$
G_{r}^{E}=\left[\begin{array}{l}
E_{1}+E_{2} P_{r}+\left(E_{3}+E_{4} P_{r}\right) T_{r}+E_{5} / T_{r}+E_{6} / T_{r}^{2} \\
+(2 x-1)\left(E_{4}+E_{8} P_{r}+\left(E_{9}+E_{10} P_{r}\right) T_{r}+E_{11} / T_{r}+E_{12} / T_{r}^{2}\right) \\
+(2 x-1)^{2}\left(E_{13}+E_{14} P_{r}+E_{15} / T_{r}+E_{16} / T_{r}^{2}\right)
\end{array}\right](1-x) x
$$

The coefficients in the above equations are shown in Table 2 [23].

Table 2 Coefficients for the Gibbs excess energy function

\begin{tabular}{cc}
\hline Coefficients & Value \\
\hline$E_{1}$ & $-4.626129 \mathrm{e} 1$ \\
$E_{2}$ & $2.060225 \mathrm{e}-2$ \\
$E_{3}$ & 7.292369 \\
$E_{4}$ & $-1.032613 \mathrm{e}-2$ \\
$E_{5}$ & $8.074842 \mathrm{e} 1$ \\
$E_{6}$ & $-8.461214 \mathrm{e} 1$ \\
$E_{7}$ & $2.452882 \mathrm{e} 1$ \\
$E_{8}$ & $9.598767 \mathrm{e}-3$ \\
\hline
\end{tabular}




\begin{tabular}{cc}
\hline$E_{9}$ & -1.475383 \\
$E_{10}$ & $-5.038107 \mathrm{e}-3$ \\
$E_{11}$ & $-9.640398 \mathrm{e} 1$ \\
$E_{12}$ & $1.226973 \mathrm{e} 2$ \\
$E_{13}$ & -7.582637 \\
$E_{14}$ & $6.012445 \mathrm{e}-4$ \\
$E_{15}$ & $5.487018 \mathrm{e} 1$ \\
$E_{16}$ & $-7.667596 \mathrm{e} 1$ \\
\hline
\end{tabular}

In order to estimate the thermodynamic properties for the two phase mixture, it is necessary to define the dryness first:

$$
\text { dryness }=\frac{x-x_{l}}{x_{g}-x_{l}}
$$

Then the two phase mixture properties are calculated using the following equations,

$$
\begin{gathered}
h_{t w o-\text { phase }}=h_{l}+\text { dryness } \times h_{g} \\
s_{t w o-\text { phase }}=s_{l}+\text { dryness } \times s_{g} \\
v_{\text {two-phase }}=v_{l}+\text { dryness } \times v_{g}
\end{gathered}
$$

At this point, the equations for the ammonia-water mixture properties from single liquid phase to single vapor phase have been obtained. To complete the set of equations, it is necessary to have expressions for the mixture bubble and dew point temperatures as function of pressure and ammonia mass fraction. These equations are addressed in the following section.

\subsection{Ammonia-water mixture bubble temperature and dew temperature}

The ammonia-water mixture bubble temperature and dew temperature are calculated using the empirical equations (25) and (26) developed by Patek and Klomfar [13]. These empirical equations make the code avoid an iterative procedure.

$$
\begin{gathered}
T(p, x)=T_{0} \sum_{i} a_{i}(1-x)^{m_{i}}\left[\ln \frac{p_{0}}{p}\right]^{n_{i}} \\
T(p, y)=T_{0} \sum_{i} a_{i}(1-y)^{m_{i} / 4}\left[\ln \frac{p_{0}}{p}\right]^{n_{i}}
\end{gathered}
$$

The equations (25) and (26) are used to calculate the mixture bubble temperature and dew temperature, respectively. In the above equations, the reference pressures $P_{0}$ is equal to $2 \mathrm{MPa}$, 
while the reference temperature $T_{0}$ is $100 \mathrm{~K}$. The coefficients used in the equations are shown in Table 3 and Table 4.

Table 3 Exponents and coefficients of the bubble equation

\begin{tabular}{cccc}
\hline $\boldsymbol{i}$ & $\boldsymbol{m}_{\boldsymbol{i}}$ & $\boldsymbol{n}_{\boldsymbol{i}}$ & $\boldsymbol{a}_{\boldsymbol{i}}$ \\
\hline 1 & 0 & 0 & $0.322302 \mathrm{e} 1$ \\
2 & 0 & 1 & -0.384206 \\
3 & 0 & 2 & $0.460965 \mathrm{e}-1$ \\
4 & 0 & 3 & $-0.378945 \mathrm{e}-2$ \\
5 & 0 & 4 & $0.135610 \mathrm{e}-3$ \\
6 & 1 & 0 & 0.487755 \\
7 & 1 & 1 & -0.120108 \\
8 & 1 & 2 & $0.106154 \mathrm{e}-1$ \\
9 & 2 & 3 & $-0.533589 \mathrm{e}-3$ \\
10 & 4 & 0 & $0.785041 \mathrm{e} 1$ \\
11 & 5 & 0 & $-0.115941 \mathrm{e} 2$ \\
12 & 5 & 1 & $-0.523150 \mathrm{e}-1$ \\
13 & 6 & 0 & $0.489596 \mathrm{e} 1$ \\
14 & 13 & 1 & $0.421059 \mathrm{e}-1$ \\
\hline
\end{tabular}

Table 4 Exponents and coefficients of the dew equation

\begin{tabular}{cccc}
\hline $\boldsymbol{i}$ & $\boldsymbol{m}_{\boldsymbol{i}}$ & $\boldsymbol{n}_{\boldsymbol{i}}$ & $\boldsymbol{a}_{\boldsymbol{i}}$ \\
\hline 1 & 0 & 0 & $0.324004 \mathrm{e} 1$ \\
2 & 0 & 1 & -0.395920 \\
3 & 0 & 2 & $0.435624 \mathrm{e}-1$ \\
4 & 0 & 3 & $-0.218943 \mathrm{e}-2$ \\
5 & 1 & 0 & $-0.143526 \mathrm{e} 1$ \\
6 & 1 & 1 & $0.105256 \mathrm{e} 1$ \\
7 & 1 & 2 & $-0.719281 \mathrm{e}-1$ \\
8 & 2 & 0 & $0.122362 \mathrm{e} 2$ \\
9 & 2 & 1 & $-0.224368 \mathrm{e} 1$ \\
10 & 3 & 0 & $-0.201780 \mathrm{e} 2$ \\
11 & 3 & 1 & $0.110834 \mathrm{e} 1$ \\
12 & 4 & 0 & $0.145399 \mathrm{e} 2$ \\
13 & 4 & 2 & 0.644312 \\
14 & 5 & 0 & $-0.221246 \mathrm{e} 1$ \\
15 & 5 & 2 & -0.756266 \\
16 & 6 & 0 & $-0.135529 \mathrm{e} 1$ \\
17 & 7 & 2 & 0.183541 \\
\hline
\end{tabular}


The equations described in this and previous chapters have then implemented in the AWProC code. A flow chart of the code is presented in Figure 4.

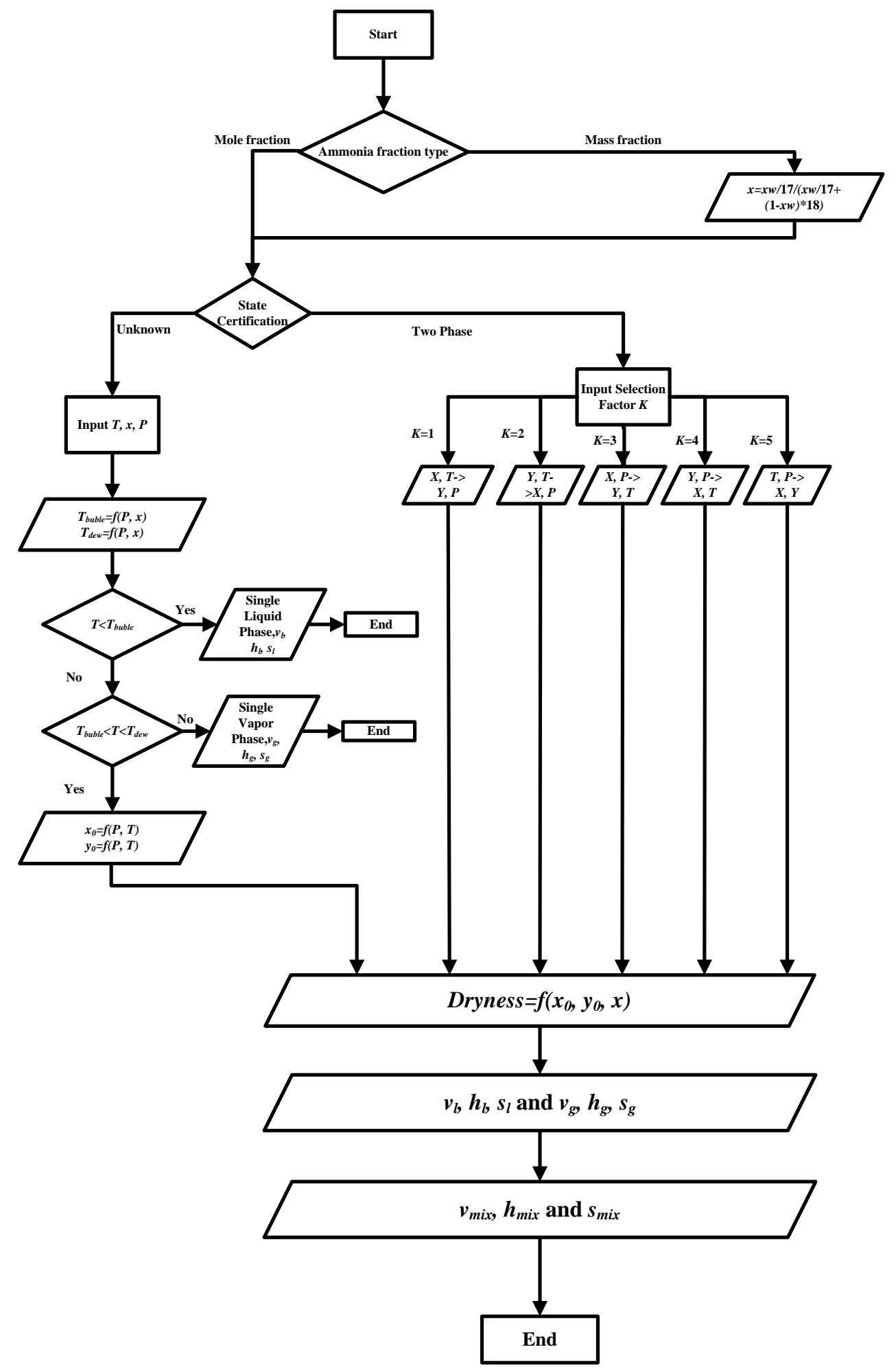

Fig. 4 Flow chart of AWProC 
The AWProC is developed using FORTRAN language and it can be used to calculate ammoniawater mixture property continuously from single phase liquid to single phase vapor. The bubble temperature and dew temperature can be calculated as well In addition, when the mixture is in two phase state, the different ammonia mass fraction in the liquid phase and vapor phase can be obtained at the given conditions.

\section{Code verification and validation}

The AWProC code has been verified and validated by comparing the code results against published data, both experimental and computational.

\subsection{Bubble Temperature and Dew Temperature}

The bubble temperature and dew temperature calculated using AWProC are compared with the IGT experimental data [24], and presented in Figure 5. As shown in the figure, the code calculation results are in very good agreement with the IGT data. The bubble point and dew point temperatures decrease with increasing ammonia mass fraction. When the ammonia mass fraction is not equal to 0.0 or 1.0 (pure water or pure ammonia respectively), the mixture bubble temperature and dew temperature are different, leading to different ammonia mass fractions in vapor and liquid phase respectively when the mixture is in two phase. It is clear to see the difference between the bubble temperature and dew temperature, which is a main factor leading to a high efficiency for Kalina cycle.

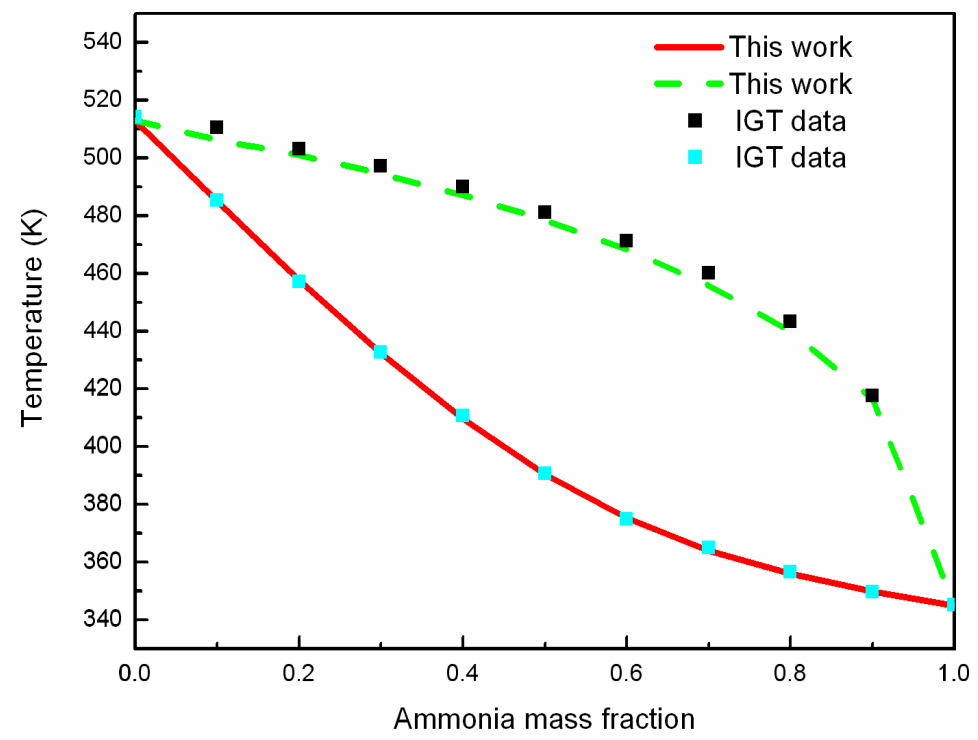

Fig. 5 Bubble and dew temperatures at 3.447 MPa vs. ammonia mass fraction 


\subsection{Specific Enthalpy and Entropy}

The specific enthalpy and entropy are significant and necessary parameters to perform the thermodynamic cycle calculation. Figures 6 (a) and (b) show the comparisons between AWProC calculated results and the IGT of the saturated liquid at 3.447 MPa and vapor enthalpy at 1.8 $\mathrm{MPa}$. As shown in the figures, the code calculation results in this work agree with the experimental data very well. It demonstrates that the ammonia-water mixture specific enthalpy can be simulated accurately using AWProC. Also, seen from the figures, the mixture liquid specific enthalpy declines with the ammonia mass fraction and it reaches a lowest value when the ammonia mass fraction is between 0.6 and 0.7 . Then the specific enthalpy begins to increase until the ammonia mass fraction reaches 1.0. The vapor specific enthalpy decreases with an increase of the ammonia mass fraction as shown in the Figure 6 (b).

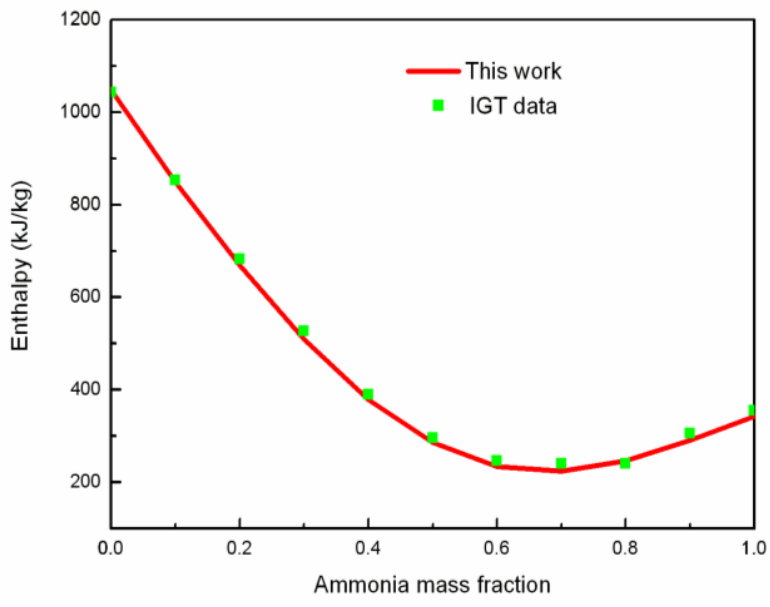

(a) Saturated liquid at $3.447 \mathrm{MPa}$

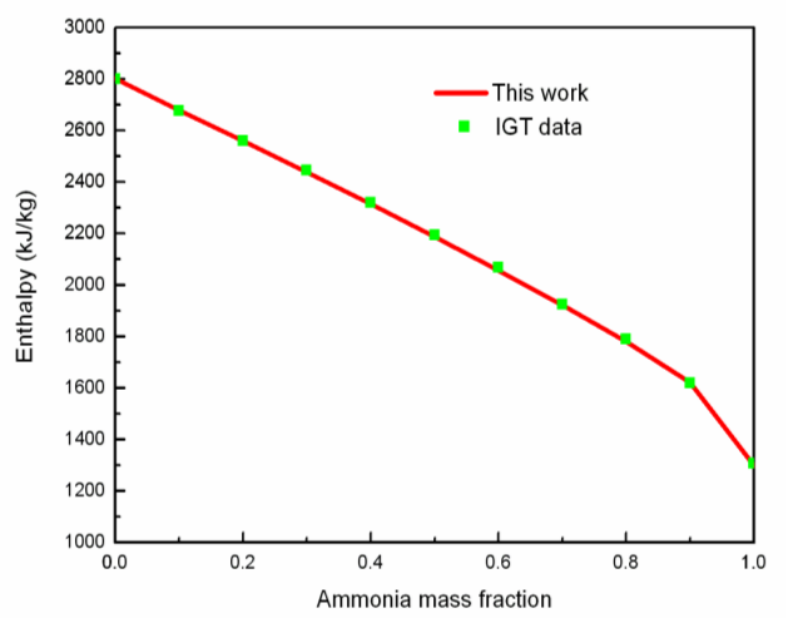

(b) Saturated vapor at $1.8 \mathrm{MPa}$

Fig. 6 Specific enthalpy vs. ammonia mass fraction

The saturated liquid and vapor entropy of the AWProC calculation results is compared with the data from [25], [26] and [25] respectively, which are shown in Figure 7 (a) and Figure 7 (b). The code calculation results in this work are in good agreement with the experimental data when the saturated liquid is at $3.447 \mathrm{MPa}$ and the saturated vapor is at $1.8 \mathrm{MPa}$. However, the entropy calculation results between different researchers are different and at an acceptable range. As can be seen in the figures, the mixture liquid specific enthalpy declines with the ammonia mass fraction and it reaches a lowest value when the ammonia mass fraction is around 0.5 and then the specific enthalpy begins to increase until the ammonia mass fraction reaches 1.0. In comparison, the vapor specific enthalpy decreases with an increase of the ammonia mass fraction as shown in the Figure 7 (b). 


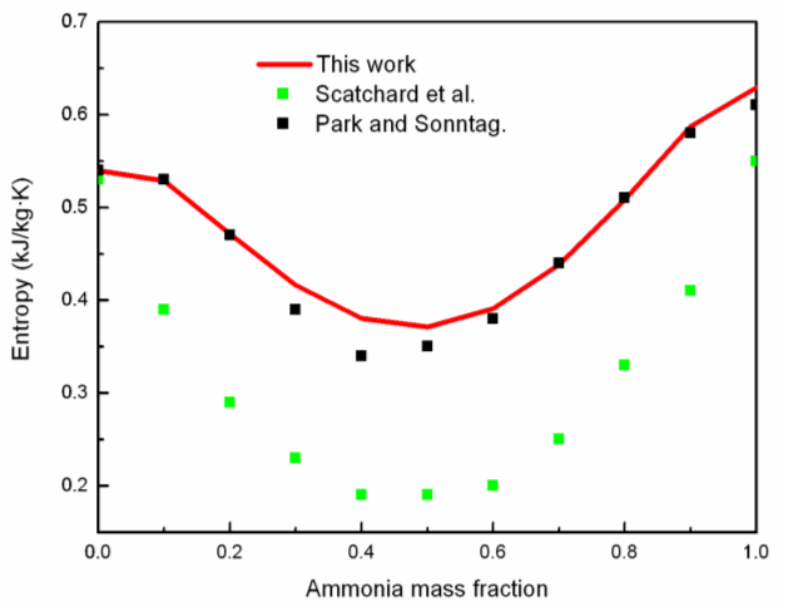

(a) Saturated liquid at $3.447 \mathrm{MPa}$

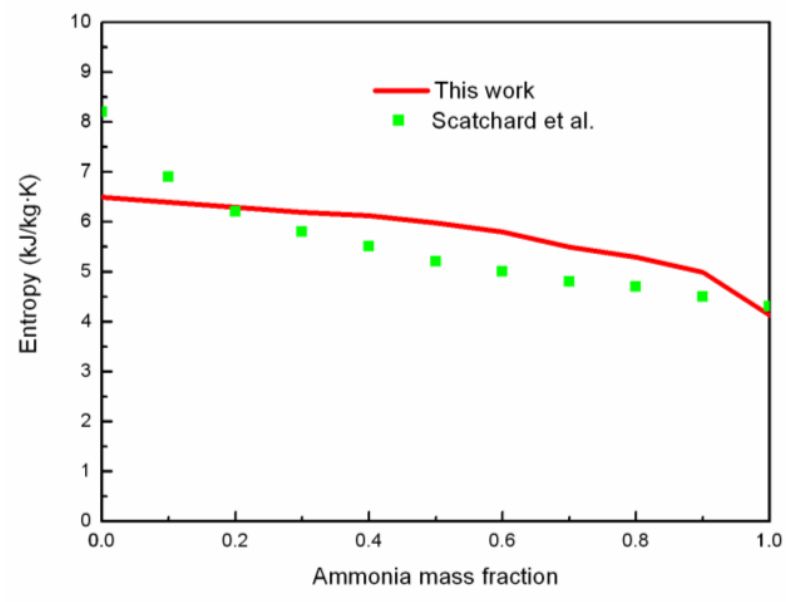

(b) Saturated vapor at $1.8 \mathrm{MPa}$

Fig. 7 Specific entropy vs. ammonia mass fraction

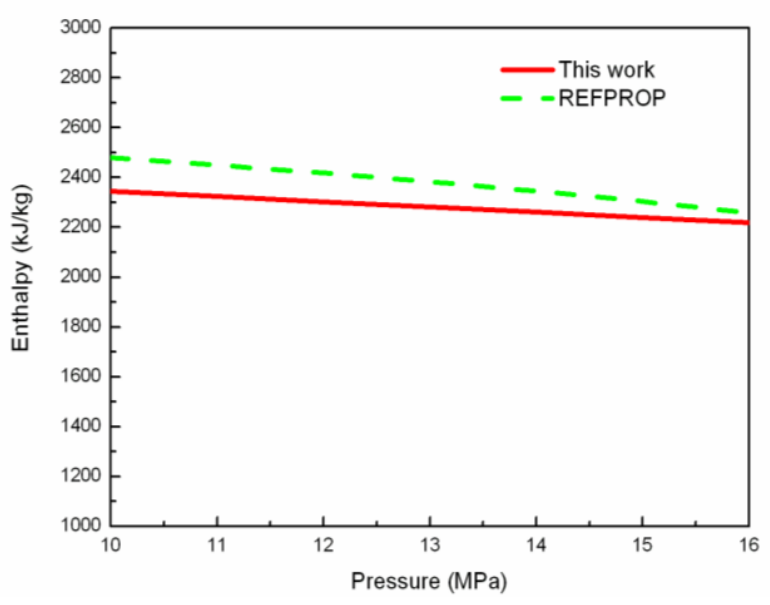

(a) Specific enthalpy

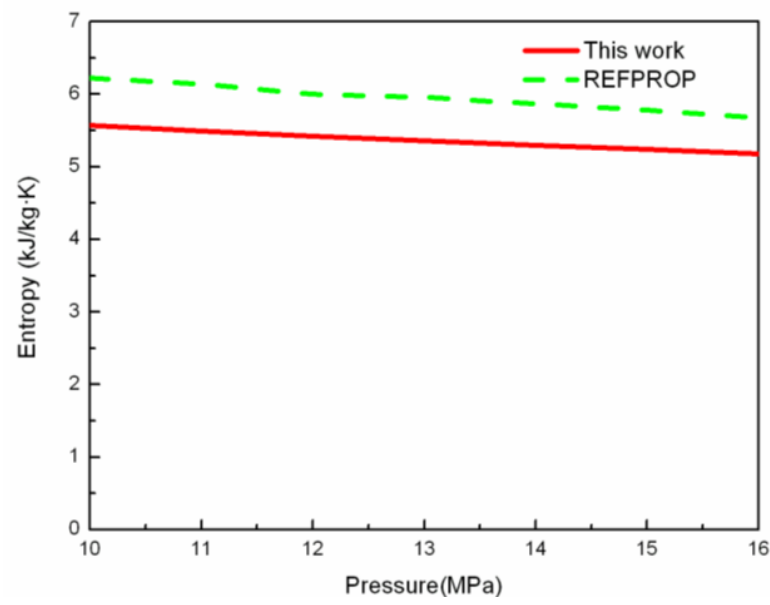

(b) Specific entropy

Fig. 8 Properties comparison at $570 \mathrm{~K}$ vs. pressure

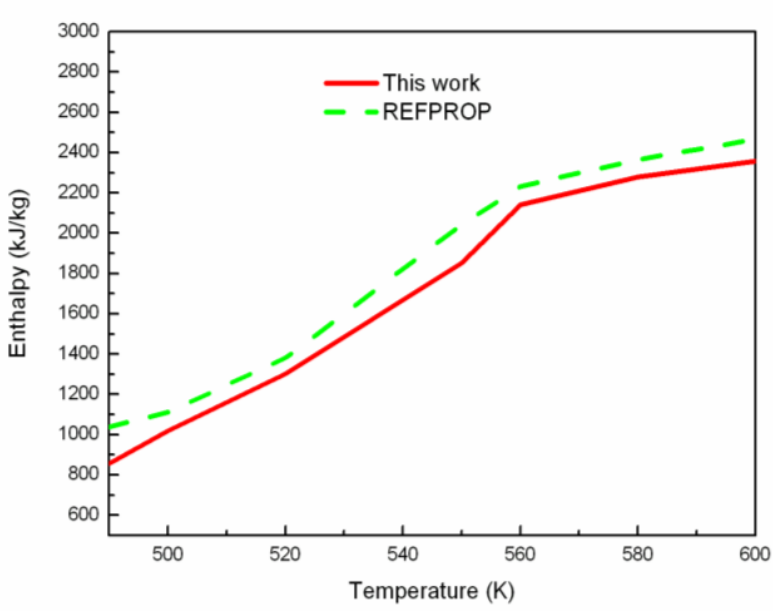

(a) Specific enthalpy

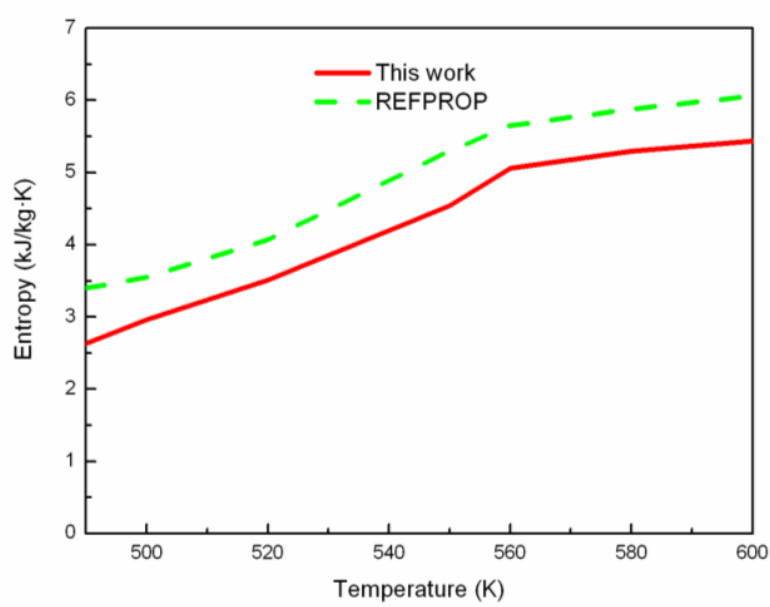

(b) Specific entropy

Fig. 9 Properties comparison at $15 \mathrm{MPa}$ vs. temperature 


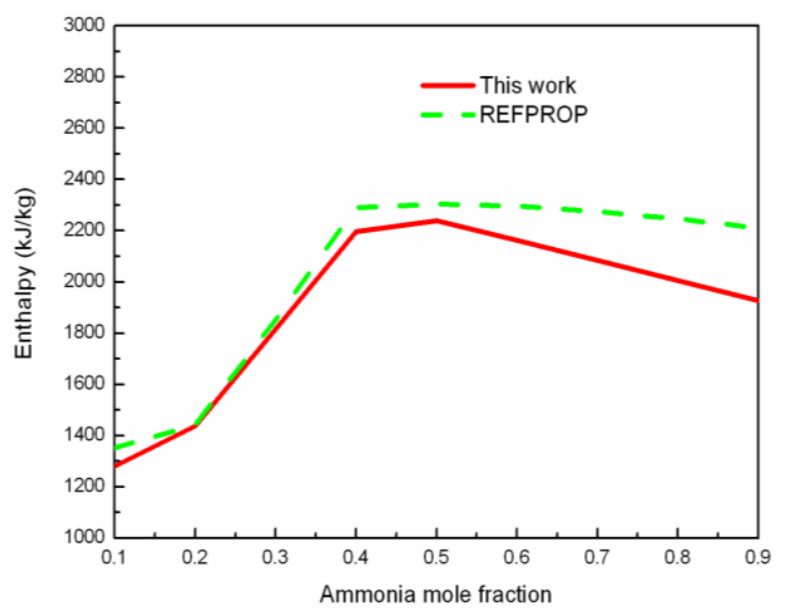

(a) Specific enthalpy

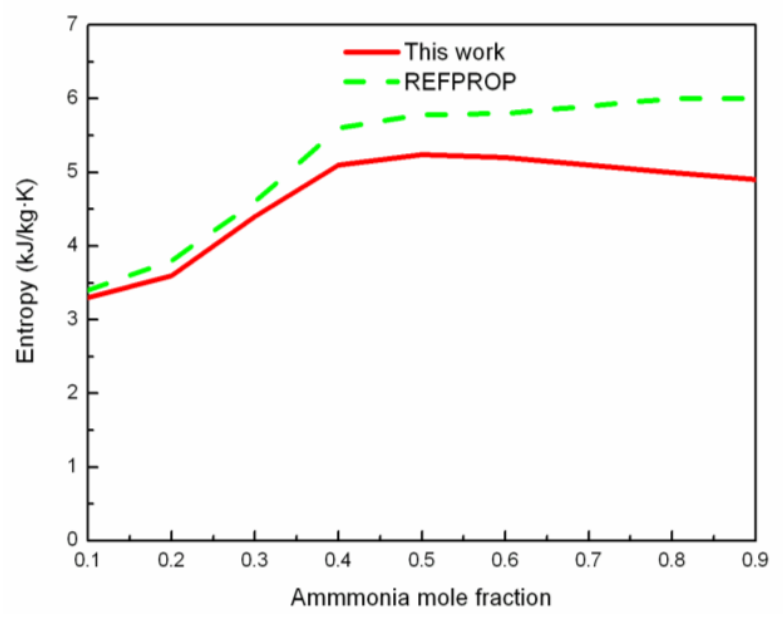

(b) Specific entropy

Fig. 10 Properties comparison at $15 \mathrm{MPa}$ and $570 \mathrm{~K}$ vs. ammonia mole fraction

The property estimation comparisons between AWProC and REFPROP code are also studied at the high temperature and pressure region in this section. Figure 8 shows the results comparison between AWProC and REFPROP code at $570 \mathrm{~K}$ with an increase of pressure from $10 \mathrm{MPa}$ to $16 \mathrm{MPa}$. The specific enthalpy and entropy variations with temperature at $15 \mathrm{MPa}$ are shown in Figure 9. Figure 10 illustrates the specific enthalpy and entropy variations with ammonia mole fraction at the specific state, $15 \mathrm{MPa}$ and $570 \mathrm{~K}$. The results show that AWProC estimation results are in good agreement with REFPROP code and the AWProC can be used to estimate the ammonia water property at high temperature and high pressure region.

\section{Kalina cycle design}

\subsection{Kalina cycle description}

The simplified Kalina cycle is basically a "modified" Rankine cycle which uses a mixture of water-ammonia as working fluid. Its configuration is depicted in Figure 11. As shown in the diagram, the secondary cycle is heated by the primary side of the steam generator $(5,6)$ through the boiler. The ammonia-water mixture is heated to superheated vapor (1), and expands in the turbine to generate electricity. The turbine exhaust (2) is cooled and condensed in the condenser by cooling water $(7,8)$. Then the saturated liquid ammonia-water mixture (3) is compressed to a high pressure through the pump (4). At last the mixture flows back to the boiler to remove heat from the primary side of the steam generator. The most significant characteristic is the variation 
of the boiling temperature and dew temperature and higher efficiency associated to absorbing and rejecting heat.

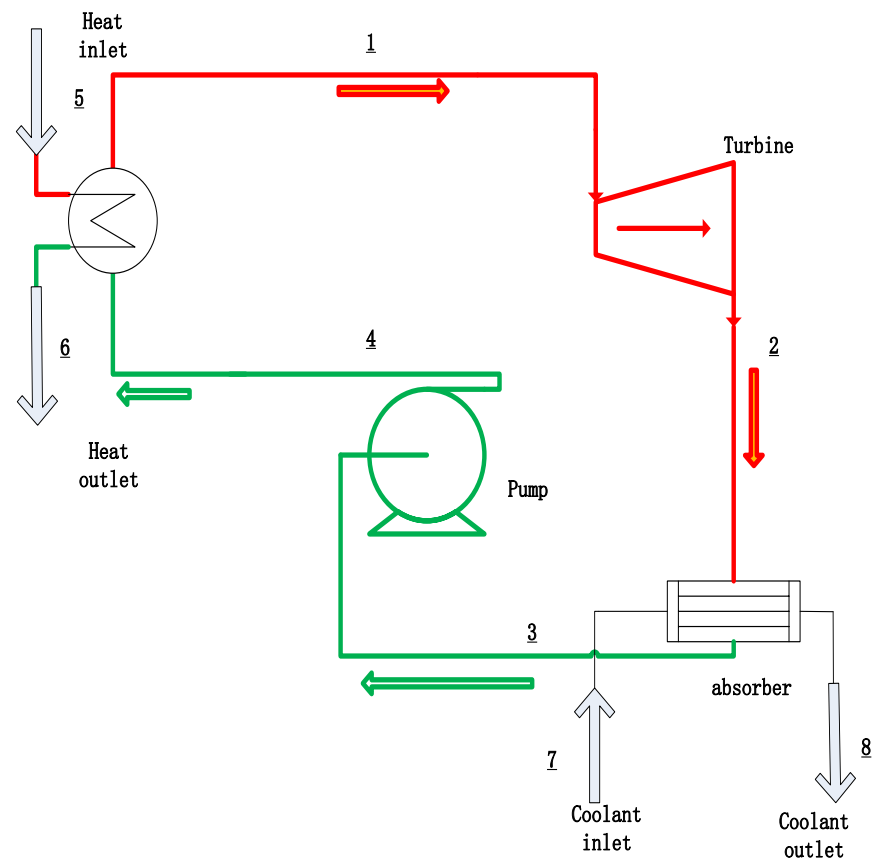

Fig. 11 Basic Kalina (B-K) type cycle configuration

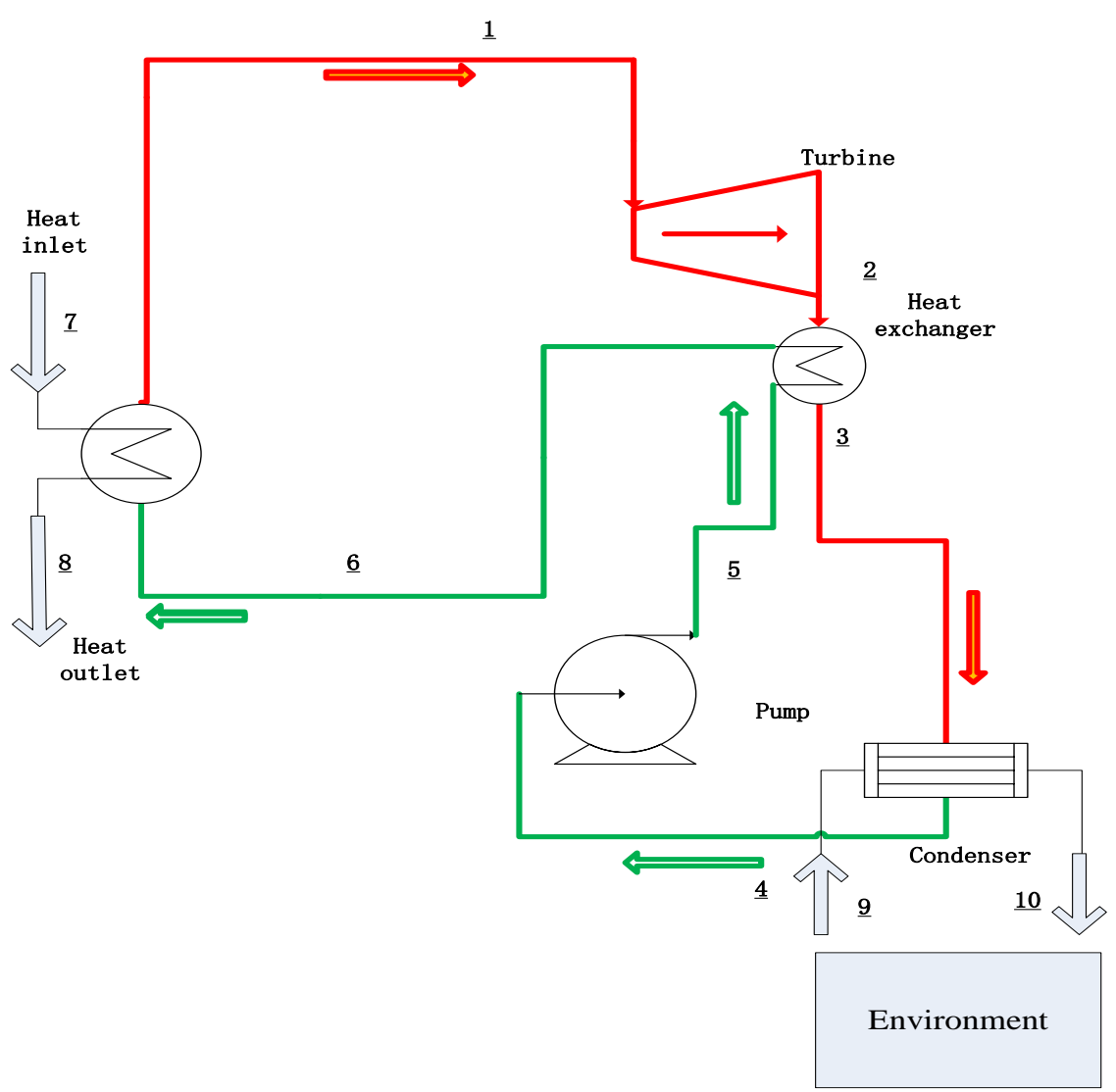


Fig. 12 Recuperation Kalina (R-K) type cycle configuration

To take advantage of the Kalina cycle, two modified configurations, Recuperation Kalina (R-K) and Flash Kalina (F-K) types respectively, are proposed and applied to a typical 1000e MW PWR plant. The two cycles are shown in Figure 12 and Figure 13 respectively.

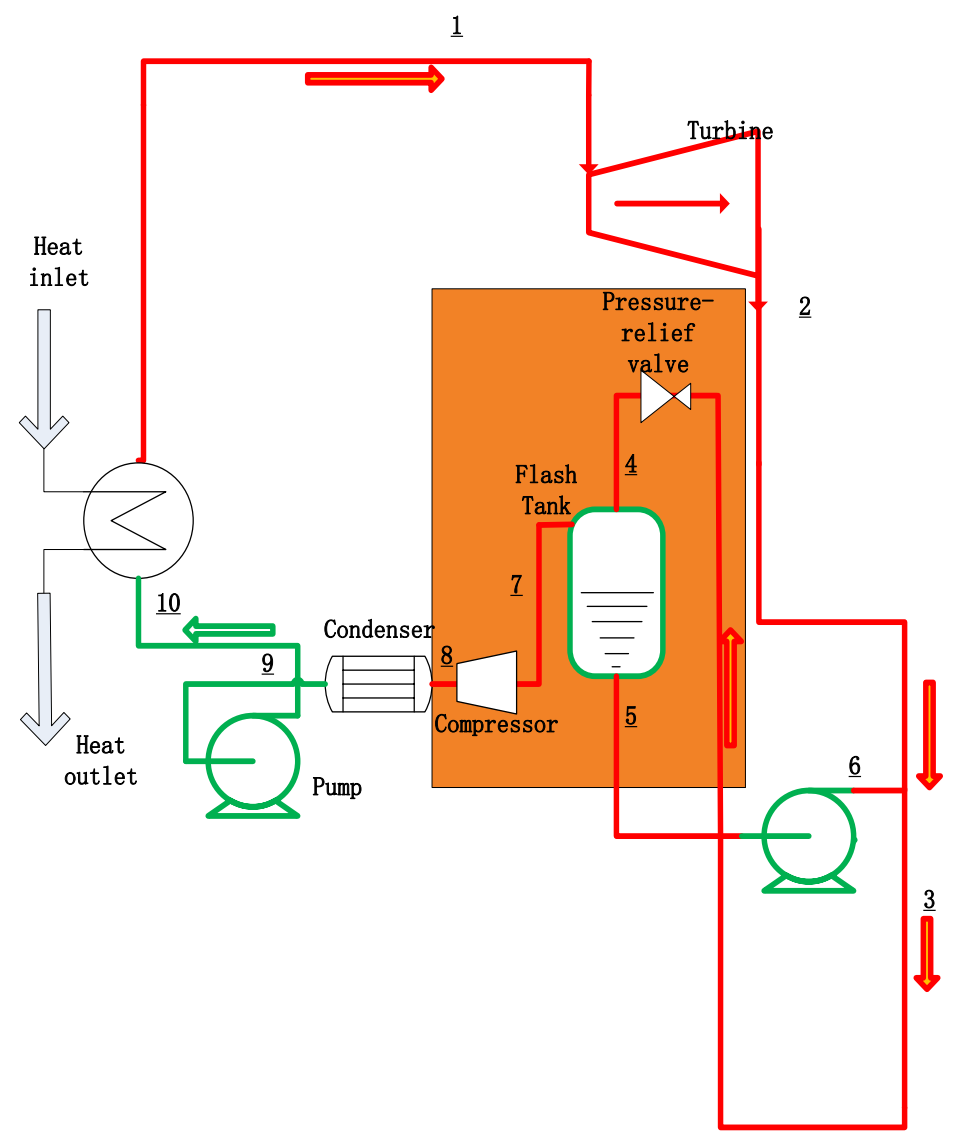

Fig. 13 Flash Kalina (F-K) type cycle configuration

The R-K type includes a heat exchanger, in which the single phase liquid is heated by the turbine exhaust. The ammonia mole fraction of mixture used in this study is 0.8 . The pressure is $15.5 \mathrm{MPa}$ and the corresponding temperature is $560.0 \mathrm{~K}$. Through the turbine expansion, the mixture pressure and temperature decrease and then flows to condenser. After pumping, the mixture flows to the heat exchanger. Then the heated ammonia-water mixture goes back to the boiler. The R-K type can utilize the exhaust heat and reduce the heat loss, leading to increase of the cycle efficiency.

For the F-K type shown in Figure 13, an incubator, pressure-relief valve, flash tank and compressor are adopted to further improve the cycle efficiency. The pressure-relief valve is 
adopted in order to decrease the pressure of the mixture at the exit of the turbine to achieve twophase flows. The two phase ammonia-water mixture is then separated in the flash tank, in order to get a mixture vapor rich in ammonia and a mixture liquid weak in ammonia. The mixture liquid weak in ammonia is later mixed with the turbine exhaust, decreasing the turbine back pressure for a higher efficiency. In order to keep the mixture flowing through the pressure-relief valve at a constant temperature, a heat insulated box is designed to utilize the compressor heat release.

\subsection{Efficiency Analysis}

In this section, a three-loop 1000MWe PWR is taken as reference plant. The heat transferred from the primary to the secondary side in each loop is calculated based on the energy conservation reported in equations (27) and (28). The boundary and initial conditions assumed

for the Kalina cycle are listed in Table 5. The in-house code AWProC is used to calculate the ammonia-water mixture properties in every node state of the Kalina cycle.

$$
\begin{aligned}
Q_{1-2} & =c_{p 1} \Delta T_{1} m_{1} \\
\Delta h_{2} & =Q_{1-2} / m_{2}
\end{aligned}
$$

Table 5 Boundary conditions for the Kalina cycle

\begin{tabular}{lc}
\hline \multicolumn{1}{c}{ Parameters } & Value \\
\hline Primary side flowrate & $23790 \mathrm{~m}^{3} / \mathrm{h}$ \\
Primary side inlet temperature & $327^{\circ} \mathrm{C}$ \\
Primary side outlet temperature & $293{ }^{\circ} \mathrm{C}$ \\
Primary side pressure & $15.5 \mathrm{MPa}$ \\
Primary side coolant specific volume & $0.00144 \mathrm{~m}^{3} / \mathrm{kg}$ \\
Secondary side pressure & $6.89 \mathrm{MPa}$ \\
Secondary side flowrate & $400 \mathrm{~kg} / \mathrm{s}$ \\
\hline
\end{tabular}

Based on the first law of thermodynamics, the thermal efficiency of the cycle is defined as:

$$
\eta=\frac{W_{n e t}}{Q_{i n}}
$$

where the $Q_{\text {in }}$ is the heat gain in the boiler and $W_{\text {net }}$ is the work output of the cycle. Based on the thermal balance, the different node state mixture properties of $\mathrm{B}-\mathrm{K}, \mathrm{R}-\mathrm{K}$ and $\mathrm{F}-\mathrm{K}$ cycles are calculated. The results are shown in Table 6, 7 and 8 , respectively. 
Table 6 Node state of working medium in B-K configuration

\begin{tabular}{lccccc}
\hline Node & $\begin{array}{c}\boldsymbol{P} \\
(\mathbf{M P a})\end{array}$ & $\begin{array}{c}\boldsymbol{T} \\
(\mathbf{K})\end{array}$ & $\begin{array}{c}\text { Ammonia mole } \\
\text { fraction } \boldsymbol{x}\end{array}$ & $\boldsymbol{h} \mathbf{( \mathbf { k J } / \mathbf { k g } )}$ & $\begin{array}{c}\boldsymbol{s} \\
(\mathbf{k J} / \mathbf{k g} \cdot \mathbf{K})\end{array}$ \\
\hline $\mathbf{1}$ & 15.5 & 560.0 & 0.8 & 1960.035 & \\
$\mathbf{2}$ & 0.4 & 355.0 & 0.8 & 1353 & 4.81 \\
$\mathbf{3}$ & 0.4 & 278.15 & 0.8 & -104.7 & 4.1 \\
$\mathbf{4}$ & 15.5 & 278.15 & 0.8 & -92.448 & 0.99 \\
\hline
\end{tabular}

Table 7 Node state of working medium in R-K configuration

\begin{tabular}{lccccc}
\hline Node & $\begin{array}{c}\boldsymbol{P} \\
(\mathbf{M P a})\end{array}$ & $\begin{array}{c}\boldsymbol{T} \\
(\mathbf{K})\end{array}$ & $\begin{array}{c}\text { Ammonia } \\
\text { mole fraction } \boldsymbol{x}\end{array}$ & $\boldsymbol{h} \mathbf{( \mathbf { k J } / \mathbf { k g } )}$ & $\begin{array}{c}\boldsymbol{s} \\
\mathbf{( k J / k g} \cdot \mathbf{K})\end{array}$ \\
\hline $\mathbf{1}$ & 15.5 & 560.0 & 0.8 & 1960.035 & 4.81 \\
$\mathbf{2}$ & 0.4 & 355.0 & 0.8 & 1353 & 4.85 \\
$\mathbf{3}$ & 0.4 & 330 & 0.8 & 956.1 & 3.69 \\
$\mathbf{4}$ & 0.4 & 278.15 & 0.8 & -104.7 & 4.1 \\
$\mathbf{5}$ & 15.5 & 278.15 & 0.8 & -92.448 & 0.011 \\
$\mathbf{6}$ & 15.5 & 350.0 & 0.8 & 213.05 & 0.99 \\
\hline
\end{tabular}

Table 8 Node state of working medium in F-K configuration

\begin{tabular}{lccccc}
\hline Node & $\begin{array}{c}\boldsymbol{P} \\
(\mathbf{M P a})\end{array}$ & $\begin{array}{c}\boldsymbol{T} \\
(\mathbf{K})\end{array}$ & $\begin{array}{c}\text { Ammonia mole } \\
\text { fraction } \boldsymbol{x}\end{array}$ & $\boldsymbol{h} \mathbf{( \mathbf { k J } / \mathbf { k g } )}$ & $\begin{array}{c}\boldsymbol{s} \\
(\mathbf{k J} / \mathbf{k g} \cdot \mathbf{K})\end{array}$ \\
\hline $\mathbf{1}$ & 15.5 & 575.0 & 0.81 & 2009.419 & 4.903 \\
$\mathbf{2}$ & 0.2 & 335.0 & 0.81 & 1279.6 & 4.926 \\
$\mathbf{3}$ & 0.2 & 332.66 & 0.49 & 581.6 & 2.49 \\
$\mathbf{4}$ & 0.08 & 330.0 & 0.49 & 912.1 & 3.68 \\
$\mathbf{5}$ & 0.08 & 330.0 & 0.13 & 147.74 & 0.79 \\
$\mathbf{6}$ & 0.2 & 330.0 & 0.13 & 147.83 & 0.79 \\
$\mathbf{7}$ & 0.08 & 330.0 & 0.81 & 1654.38 & 6.45 \\
$\mathbf{8}$ & 1.8 & 330.0 & 0.81 & 781.1 & 2.88 \\
$\mathbf{9}$ & 1.8 & 328.0 & 0.81 & 117.13 & 0.75 \\
$\mathbf{1 0}$ & 15.5 & 328.0 & 0.81 & 121.74 & 0.75 \\
\hline
\end{tabular}

For the B-K and R-K types, the temperatures of node 1 could not increase to a higher value due to the turbine isentropic increase process limitation. Also, the pressures of node 2 could not be lower because the environmental temperature limit. The lower pressure in R-K type with the ammonia mole fraction 0.8 makes the mixture unrealistic condensation. However, for the F-K type, because of the lower ammonia mole fraction with the lean ammonia mixture flowing back, 
the mixture can condense in lower pressure condition. Then from the node state parameters from above tables, the B-K, R-K and F-K type cycles efficiencies are obtained based on the first law of thermodynamics. The turbine efficiency is assumed as $90 \%$ in this study to make it more realistic. Then he computed efficiencies are $26.6 \%, 31.2 \%$ and $34.8 \%$ respectively. As shown in tables, unpractical low temperatures are required in the first two cycle condensers. Therefore, the F-K type has therefore the potential to improve the thermal efficiency of a nuclear power plant.

\section{Conclusion}

The thermal efficiency is a significant factor to be considered during the design of a nuclear power plant, in order to enhance the competitiveness of nuclear energy.

In this work, the AWProC, which is derived from the Gibbs free energy functions and can be used to calculate the ammonia-water mixture properties in both single phase and two phases, is developed in this work. And through comparison with experimental data published in the literature and the REFPROP code, it demonstrates that the AWProC is available and can be used in future ammonia water mixture property calculation at a broad range of pressures and temperatures.

Also, it is demonstrated that the innovative concept of a Kalina cycle can be applied to the operating conditions of a typical light water reactor in order to increase the overall plant thermodynamic efficiency.

In particular three variants of the Kalina cycles are analyzed (B-K, R-K and F-K types respectively) and applied to a typical 1000MWe PWR plants. A thermal efficiency up to $34.8 \%$ has been achieved. Even though additional studies are necessary to further increase the cycle efficiency and make Kalina cycle apply in the PWR plants, including the ammonia water mixture heat transfer and flow characteristic, HX heat transfer and turbine expansion process, the present study has shown that the Kalina has very good potentials for the nuclear industry.

\section{Acknowledgement}


This research has been supported by the Chinese Scholarship Council and by the DOE Office of Nuclear Energy's Nuclear Energy University Programs (NEUP).

\section{References}

[1] Kalina AI. Generation of energy by means of a working fluid, and regenera- tion of a working fluid. United States Patent 4346561. Filed date: Aug. 31, 1982.

[2] Kalina AI. Combined cycle and waste heat recovery power systems based on a novel thermodynamic energy cycle utilizing low-temperature heat for power generation. American Society of Mechanical Engineers, 1983, New York, Paper No. 83-JPGC-GT-3, 1-5.

[3] Kalina AI. Combined-cycle system with novel bottoming cycle. ASME Journal of Engineering for Gas Turbines and Power 1984; 106: 737-742.

[4] Mlcak HA. An introduction to the Kalina Cycle. PWR-Vol. 30, Proceedings of the International Joint Power Generation Conference, 1996, Houston, Texas.

[5 ]Yutaka Takeuchi, Hirozo Shiomi, Nobuhiko Miyamae, Miki Hiramatsu, Mistuto Montani and Iwao Ohshima. Feasibility study for application of mixture working fluid cycle to nuclear reactor power plant. 7th International Conference on Nuclear Engineering. Tokyo, Japan, April 19-23, 1999: 1-8.

[6] Zhao E, Sugie H, Lu BCY. Calculation of vapor-liquid equilibria and saturated liquid volumes for water-ammonia mixtures. Chemical Engineering Com- munication 1994; 129: 99108.

[7] Duan Z, Møller N, Weare JH. Equation of state for the NH3-H2O system. Journal of Solution Chemistry 1996; 25: 43-50.

[8] Xu F, Goswami YD. Thermodynamic properties of ammonia-water mixtures for power-cycle applications. Energy 1999; 24(6): 525-536.

[9] Nowarski A, Friend DG. Application of the extended corresponding state method to the calculation of the ammonia-water mixture thermodynamic surface. International Journal of Thermophysics 1998; 19(4): 1133-1142.

[10] Abovsky V. Thermodynamics of ammonia-water mixture. Fluid Phase Equilibria 1996; 116: 170-176.

[11] Enick RM, Mcllvried HG, Gale TK, Klara JM. The modeling of LEBS Kalina power cycles. Proceedings of Joint Power Generation conference, ASME 1997; 2: 55-67. 
[12] Rainwater JC, Tillner-Roth R. Critical region vapor-liquid equilibrium model of ammoniawater.13th International Conference on the Properties of Water and Steam, 1999, Toronto, Canada.

[13] Tillner-Roth R, Friend DGA. Helmholtz free energy formulation of the thermodynamic properties of the mixture (water+ammonia). Journal of Physical and Chemical Reference Data 1998; 27(1b): 63-69.

[14] Pate`k J, Klomfar J. Simple functions for fast calculations of selected thermodynamic properties of the ammonia-water system. International Journal of Refrigeration. 1995; 18(4): 228-234.

[15] Ziegler B, Trepp CH (1984). Equation of state for ammonia-water mixtures, Refrig., 7: 101106.

[16] Kalina AI. Novel power cycle for combined-cycle system and utility power plants(ESL-IE86-06-39). Proceedings from the eighth annual industrial energy technology conference, Houston, TX, June 17-19, 1986.

[17] Hettiarachchi HDM, Golubovic M, Worek WM. The performance of the Kalina cycle system 11 (KCS-11) with low-temperature heat sources. J Energy Resour Technol 2007; 129(3): 243-247.

[18] X. Li, Q. Zhang, X. Li. A Kalina cycle with ejector. Energy, 2013, 54: 212-219

[19] Zhang XX, He MG, Zhang Y. A review of research on the Kalina cycle. Renew Sust Energ Rev 2012; 16(7): 5309-5318.

[20] Rogdakis ED, Antonopoulos KA. A high efficiency NH3/H2O absorption power cycle. Heat Recovery Systems 1991; II: 263-275.

[21] Koremenos DA, Rogdakis ED, Antonopoulos KA. Cogeneration with combined gas and aqua-ammonia absorption cycles. In: Krane RJ, editor. Thermodynamics and The Design Analysis, and Improvement of Energy Systems, vol. 33. New York: ASME AES, 1994: 231-238. [22] Eric W. Lemmon, Mark O. McLinden, Marcia L. Huber. NIST Reference Fluid Thermodynamic and Transport Properties-REFPROP. NIST Standard Reference Database 23. Aug. 2002.

[23] N. Shankar Ganesh, T. Srinivas. Evaluation of thermodynamic properties of ammonia-water mixture up to 100 bar for power application systems. Journal of Mechanical Engineering Research 2011; 3(1): 25-39. 
[24] Macriss, R.A., Eakine, B.E., Ellington, R.T. and Huebler J. 1964. Physical and thermodynamic properties of ammonia-water mixtures. Research Bulletin No. 34. Institute of Gas Technology, Chicago (IL), USA.

[25] Scatchard, G., Epstein, L.F., Warburton, J. and Cody, P.J. 1947. Thermodynamic properties saturated liquid and vapor of ammonia-water mixtures, Refrigeration Engineering. Vol. 53: 413452.

[26] Park YM, Sonntag RE. ASHRAE Trans 1992; 97: 150. 